\title{
RESEARCH
}

\section{Cost-effectiveness of self-managed versus physician-managed oral anticoagulation therapy}

\author{
Dean A. Regier, Rubina Sunderji, Larry D. Lynd, Kenneth Gin, Carlo A. Marra
}

\section{ABstRACT}

Background: Patient self-management of long-term oral anticoagulation therapy is an effective strategy in a number of clinical situations, but it is currently not a funded option in the Canadian health care system. We sought to compare the incremental cost and health benefits of self-management with those of physician management from the perspective of the Canadian health care payer over a 5 -year period.

Methods: We developed a Bayesian Markov model comparing the costs and quality-adjusted life years (QALYs) accrued to patients receiving oral anticoagulation therapy through self-management or physician management for atrial fibrillation or for a mechanical heart valve. Five health states were defined: no events, minor hemorrhagic events, major hemorrhagic events, thrombotic events and death. Data from published literature were used for transition probabilities. Canadian 2003 costs were used, and utility estimates were obtained from various published sources.

Results: Self-management resulted in 3.50 fewer thrombotic events, 0.78 fewer major hemorrhagic events and 0.12 fewer deaths per 100 patients than physician management. The average discounted incremental cost of self-management over physician management was found to be $\$ 989$ ( $95 \%$ confidence interval $[\mathrm{Cl}]$ \$310-\$1655) per patient and the incremental QALYs gained was 0.07 ( $95 \% \mathrm{Cl} 0.06-0.08)$. The cost-effectiveness of self-management was \$14 129 per QALY gained. There was a $95 \%$ chance that self-management would be cost-effective at a willingness to pay of \$23 800 per QALY. Results were robust in probabilistic and deterministic sensitivity analyses.

Interpretation: This model suggests that self-management is a cost-effective strategy for those receiving long-term oral anticoagulation therapy for atrial fibrillation or for a mechanical heart valve.

CMAJ 2006;174(13):1847-52

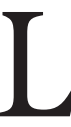

ong-term oral anticoagulation therapy with vitamin $\mathrm{K}$ antagonists is prescribed as prophylaxis against strokes and other embolic events in patients with atrial fibrillation or a mechanical heart valve. ${ }^{\mathrm{I}, 2}$ Warfarin therapy, however, is complicated by the variability of its biologic effect, its narrow therapeutic index, and the associated thrombotic or hemorrhagic events in the event of over- or underanticoagulation. ${ }^{2}$ It has been shown that improved anticoagulant control can be achieved through frequent monitoring of the international normalized ratio (INR), resulting in improved health outcomes. ${ }^{3}$

Monitoring the INR and managing warfarin dosing by a primary care physician is the current clinical standard of practice in Canada. ${ }^{4}$ Physician management requires patients to visit a laboratory regularly for INR testing. The laboratory reports the INR to the physician, who subsequently contacts the patient with any required change in dosage. An alternative strategy is patient self-management. Self-management entails the measurement of the INR by the patient using a pointof-care device and, when necessary, self-adjustment of the warfarin dose using a nomogram. ${ }^{4}$

Several published trials have compared self-management with physician management or management in an anticoagulation clinic. ${ }^{4-13}$ It has been found that patients who self-manage check their INR more frequently and are able to maintain a greater proportion of INRs within the therapeutic range compared with those whose therapy is monitored by a physician or in an anticoagulation clinic. ${ }^{\mathrm{II}-\mathrm{I} 3}$ The results of a recent meta-analysis showed a significant reduction in thromboembolic events (odds ratio [OR] 0.45), major hemorrhagic events (OR 0.65) and all-cause mortality (OR o.6I) for those using a self-management or self-test strategy. ${ }^{\mathrm{I}}$ The results also showed that self-management compared with self-testing alone reduces the occurrence of thromboembolic events (OR 0.27) and death (OR 0.37). ${ }^{14}$ These results, together with the greater initial costs of educating patients to self-manage and of the pointof-care device itself, provide the impetus for a formal costeffectiveness analysis.

The objective of this study was to evaluate the incremental cost and health benefits of self-managed versus physicianmanaged chronic oral anticoagulation therapy from the perspective of the Canadian health care payer. A Bayesian approach was adopted to facilitate the incorporation of prior knowledge of transition probabilities and for probabilistic sensitivity analysis. 


\section{Methods}

\section{Model overview}

We used a Markov decision-analytic model to compare the costs and quality-adjusted life years (QALYs) accrued to patients in a self-management or physician management strategy over a period of 5 years (online Appendix I, available at www.cmaj.ca/cgi/content/full/I847/DCI). Patients could move through 5 health states: no events (state I), minor or major hemorrhagic events (states 2 and 3), major thrombotic events (state 4) and death (state 5). Those who experienced a major hemorrhagic (state 3) or thrombotic event (state 4) were at risk of permanent disability and were switched to physician management if they were previously self-managing their therapy. The likelihood of patients changing from one health state to another depended on their time spent below, in and above therapeutic range. ${ }^{15}$ Age-specific rates for natural death were derived from life tables from Statistics Canada. ${ }^{16}$ At baseline, all patients were assumed to be in the "no events" state. The primary outcome was the incremental costeffectiveness ratio (ICER), which has incremental costs in the numerator and incremental health benefits in the denominator. Cost and effects were discounted at a rate of $3 \%$ beyond the first year. ${ }^{17}$

The model was estimated using the Bayesian specialist software WinBUGS version I.4.I (MRC Biostatistics Unit, Cambridge, United Kingdom, 2004). To incorporate probabilistic sensitivity analysis, a Dirichlet distribution was specified to represent each transition probability. ${ }^{18}$ Standard deviations for costs were generated using a triangular distribution by assuming an increase/decrease in cost by $25 \%$.

\section{Model inputs}

Estimates for time in therapeutic range were taken from a randomized controlled trial conducted at Vancouver General Hospital (VGH) that evaluated self-management and physician management of warfarin therapy in 140 patients with atrial fibrillation, a mechanical heart valve or venous thromboembolism; 13 patients in the self-management group discontinued therapy immediately after randomization. ${ }^{4}$ Optimal therapeutic ranges depended on the indication for treatment (INR 2.0-3.0 for atrial fibrillation, INR 2.0-3.0 for aortic mechanical heart valve, INR 2.5-3.5 for mitral mechanical heart valve). Patients in the self-management group were in therapeutic range a greater percentage of the time than those in the physician management group (71.8\% v. $63.2 \%$ respectively; $p=0.14$ ).

To determine the probability of an event given time in therapeutic range and to characterize prior knowledge of time in therapeutic range, we conducted a search on MEDLINE (Jan. Ig9o to Jan. 2005) for studies of directly monitored self-management or physician management with long-term vitamin $\mathrm{K}$ antagonists, therapeutic ranges similar to those in the VGH trial, and event rates related to all levels of anticoagulation ranges. No studies met the inclusion criteria for providing prior knowledge of time in therapeutic range. Esti- mates for event probabilities given time in therapeutic range were taken from a large prospective cohort study (ISCOAT) that followed 2745 consecutive patients with heart valve prostheses, atrial fibrillation or venous thromboembolism. ${ }^{19}$ To provide prior information for event transition probabilities, a study by Cannegieter and colleague ${ }^{20}$ involving patients with a mechanical heart valve was used. The probability of permanent disability after a major event was assumed to be 0.30 for thrombotic events $\mathrm{s}^{2 \mathrm{I}-23}$ and o.Io for hemorrhagic events. ${ }^{24}$

Costs were taken from the perspective of the health care payer and were reported in 2003 Canadian dollars. The costs of self-management training were obtained from a VGH fully-allocated cost model. In the VGH trial, ${ }^{4}$ one pharmacist conducted 2 training sessions lasting for a total of 5 hours. We assumed that 3 patients would attend each session, the number recommended by the International Self-Monitoring Association for Oral Anticoagulation. ${ }^{25}$ To include the costs of "training the trainer," we assumed the pharmacist would need one full work day to develop sufficient training expertise.

INR testing for physician management included I4 laboratory tests per year. ${ }^{\text {II }}$ Each test was followed by a telephone consult from the physician directly to the patient. For selfmanagement, we assumed that patients conducted weekly

Table 1: Estimated model variables

Variable

Mean ( $95 \%$ confidence interval)

Time spent below, in or above therapeutic range

Self-management

$\begin{array}{ll}\text { Below } & 0.150(0.144-0.156) \\ \text { In } & 0.718(0.710-0.725) \\ \text { Above } & 0.133(0.127-0.137)\end{array}$

Physician management

Below

$0.273(0.266-0.280)$

In

$0.632(0.624-0.639)$

Above

$0.095(0.090-0.100)$

Event rate by time below, in or above therapeutic range Thrombosis
Below
$0.120(0.09-0.14)$
In
$0.012(0.008-0.015)$
Above
0.006 (0.003-0.008)

Major hemorrhage

Below

0.004 (0.001-0.009)

In

0.005 (0.002-0.006)

Above

$0.059(0.05-0.07)$

Minor hemorrhage

Below

0.00

In

$0.040(0.034-0.045)$

Above

$0.110(0.096-0.117)$

Death

Following major thrombotic event $0.210(0.140-0.300)$

Following major hemorrhagic event $0.140(0.090-0.180)$ 
INR tests and contacted a pharmacist after each test during the first month and once a month thereafter. Patients in the self-management strategy would require one physician visit per year, and those in the physician management strategy would have 3 physician visits annually.

Resource utilization for a major thrombotic event included an emergency visit, diagnostic tests (e.g., CT scan, electrocardiogram, carotid duplex, etc.) and treatment. ${ }^{26} \mathrm{We}$ assumed that $10 \%$ of patients would receive tissue plasminogen activator. Patients having a major thrombotic event were expected to stay in hospital an average of 15.3 days. ${ }^{27}$ For major hemorrhagic events, cost data were based on a weighted average of costs for gastrointestinal bleed and intracranial hemorrhage. ${ }^{28}$ The cost of a minor hemorrhage was limited to a complete blood count, an INR test and an emergency visit.

Our primary effectiveness end point was quality-adjusted life years (QALYs). QALYs are calculated by multiplying the duration of time spent in a health state by the utility weight for that state. In the base-case analysis, utility weightings associated with each health state were derived from several sources $^{29-31}$ that administered the EQ-5D questionnaire ${ }^{32}$ to patients who experienced a major hemorrhage or stroke. In a deterministic sensitivity analysis, we examined the sensitivity of the ICER when standard gamble (SG) utility weightings ${ }^{33}$ were used for the QALYs calculation.

An EQ-5D utility score of 0.70 was assigned to those patients after stroke with no permanent disability and was calculated as a weighted average of patients with a Barthel Index score of at least $15 .{ }^{3 \mathrm{I}}$ For those with permanent disability secondary to stroke, we assumed a utility weight of 0.19 for the first year, which was based on a weighted average of those having a Barthel Index score between o (very severe) and I4 (moderate). ${ }^{3 \mathrm{I}}$ In subsequent years, patients with disability from stroke were given a utility score of $0.33 \cdot{ }^{3 \mathrm{I}} \mathrm{A}$ utility weight of 0.80 was given to patients having a major hemorrhage with no disability..$^{30}$ For those with disability, an EQ-5D weight of 0.69 was assumed..$^{\circ}$

\section{Results}

Estimates for the time in therapeutic range are presented in Table I. In the self-management strategy, patients were estimated to spend $15 \%$ of time below, $72 \%$ within and $13 \%$ above therapeutic range. Those whose therapy was physician- managed were below range $27 \%$, in range $63 \%$ and above range $10 \%$ of time. The probability of a thrombotic event if a patient was below, within or above therapeutic range was $0.12,0.012$ and 0.006 respectively. For major hemorrhagic events, the probability was $0.004,0.005$ and 0.059 for below, within and above therapeutic ranges. The probability of death given a thrombotic event was estimated to be 0.2I. After a major hemorrhage, the probability of death was 0.I4.

Start-up costs for self-managing patients were estimated to be $\$ 1567$ per patient, and the annual costs of physician management and self-management were estimated to be $\$ 357$ and $\$ 352$ respectively per patient. The total acute cost for a major thrombotic event was \$14 428. The estimated cost of a major and minor hemorrhage event was estimated to be $\$ 6003$ and $\$ 9$ I respectively. After a major event, patients with mild disability underwent one year of rehabilitation at a cost of $\$ 2176 .{ }^{34}$ For those with permanent disability, we estimated an average yearly cost of $\$ 33532$ for care. ${ }^{35}$ Costs are summarized in online Appendix 2 (www.cmaj.ca/cgi/content/full/I74 /13/1847/DC2).

Over a 5-year period, self-management was expected to result in 3.5 fewer major thrombotic events, 0.79 fewer major hemorrhagic events and 0.12 fewer deaths per roo patients than physician management (Table 2). The mean cost per patient over 5 years in the self-management strategy was \$6Ir6 ( $95 \%$ confidence interval [CI] \$5426-\$6830). In the physician management strategy, the cost per patient was $\$ 5127$ (95\% CI \$439o-\$5894). As such, the average per-patient incremental cost of self-management when compared with physician management was $\$ 989$ (95\% CI \$3IO-\$1655). In terms of quality of life, self-management resulted in 4.28 QALYs ( $95 \%$ CI 4.24-4.30) and physician management in 4.2I QALYs (95\% CI 4.19-4.25); the incremental QALY gained was 0.07 ( $95 \% \mathrm{CI} 0.056-0.084$ ) in favour of self-management. The incremental cost-effectiveness of self-managed long-term anticoagulation therapy over physician-managed was \$I4 I29 per QALY gained over 5 years.

The decision to adopt a new strategy depends upon the maximum amount that decision-makers are willing to pay to achieve a benefit. ${ }^{36}$ However, the maximum amount itself is unknown and must be varied to show how cost-effectiveness changes with willingness to pay. Fig. I illustrates the joint density of the incremental costs and benefits of each of the 20000 model iterations; uncertainty surrounding the ICER

Table 2: Expected incremental costs and health benefits of self-managed anticoagulation therapy

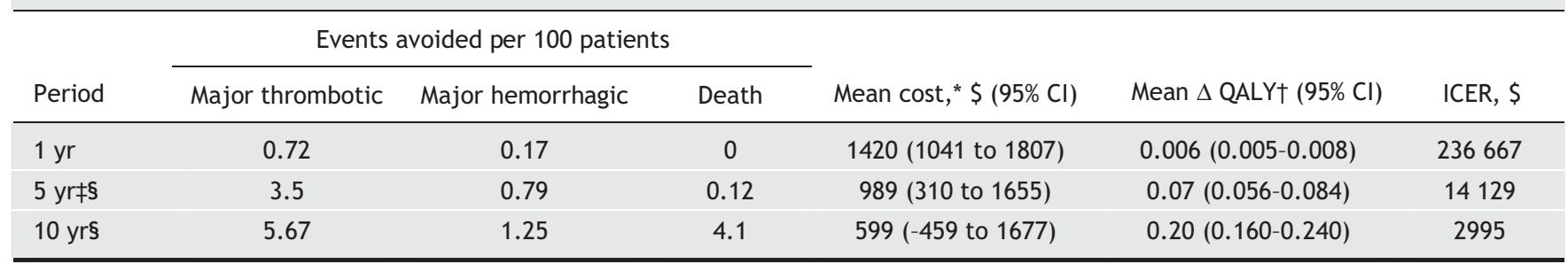

Note: $\mathrm{Cl}=$ confidence interval, QALY = quality-adjusted life years, ICER = incremental cost-effectiveness ratio. All costs are reported in 2003 Canadian dollars.

*Incremental costs for self-management strategy.

TQALYs gained for self-management strategy.

$\ddagger$ Base case time period.

§Costs and QALYs were discounted at a rate of $3 \%$ beyond the first year. 
can be summarized by considering the proportion of simulated ICERs below a given maximum amount per QALY, which is illustrated using the cost-effectiveness acceptability curve (Fig. 2). ${ }^{36}$ In the base-case analysis, there was a $95 \%$ probability that self-management was cost-effective at a willingness to pay of $\$ 23800$.

\section{Deterministic sensitivity analysis}

We conducted I-way and 2-way sensitivity analyses. Assuming no physician visits in either strategy produced an ICER of \$I9 5 I4 over 5 years. Three visits in the self-management strategy and 6 visits in the physician management strategy resulted in an ICER of \$II 428 per QALY gained. Decreasing the probability of disability from 0.30 to 0.25 after a major thrombotic event and from o.Io to 0.05 after a major hemorrhagic event increased the ICER to \$I6 207 per QALY gained.

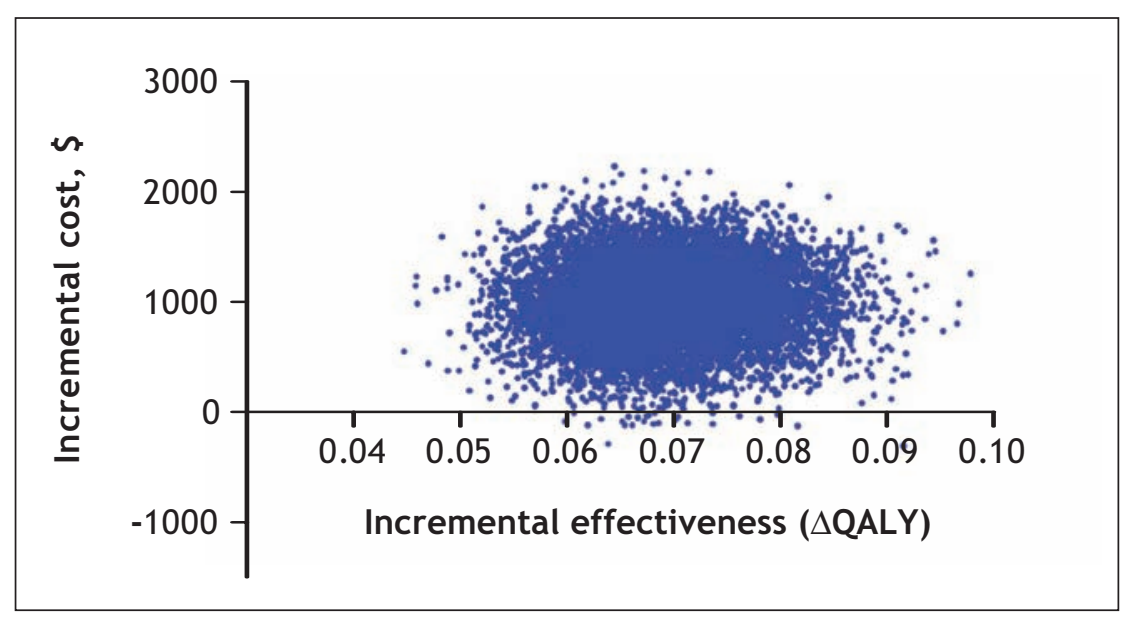

Fig. 1: Joint density of the incremental costs and benefits of each of the 20000 simulated cost-effectiveness ratios.

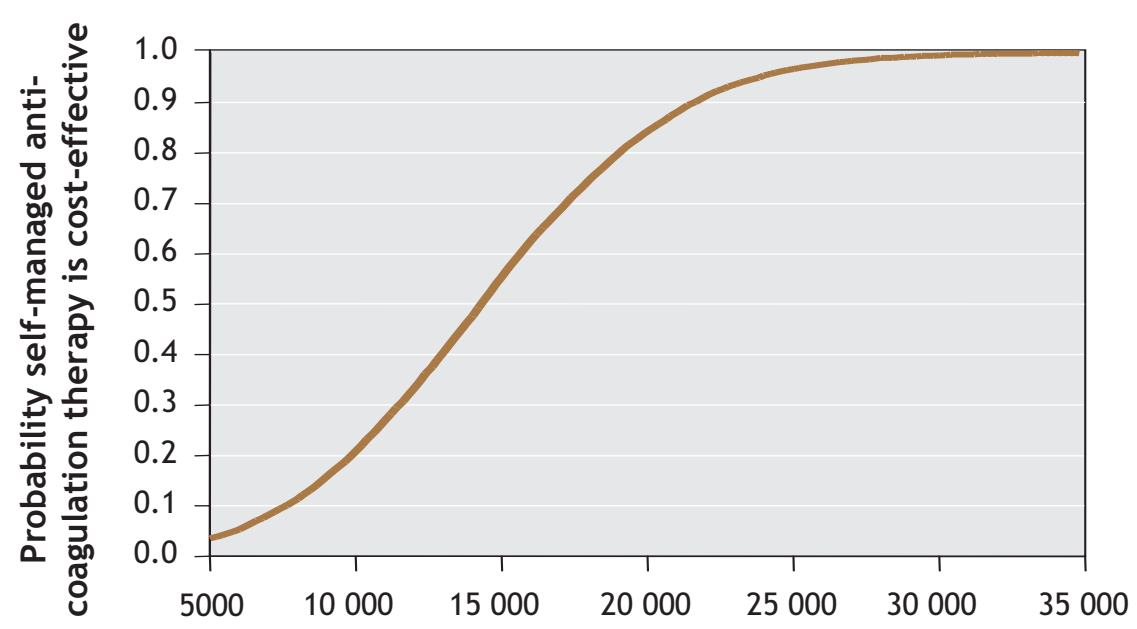

Maximum willingness to pay, \$ per QALY

Fig. 2: Cost-effectiveness acceptability curve of maximum willingness to pay for selfmanaged anticoagulation therapy versus physician-managed anticoagulation therapy.
Increasing the discount rate to $6 \%$ produced an ICER of \$I5 7I2.

The sensitivity of the ICER to the assumptions surrounding utility weightings was tested by varying the starting utility of patients and using utility weights derived from the SG technique. Assuming that self-managed and physicianmanaged patients began with a utility weighting of 0.7 resulted in 0.063 QALYs gained and increased the ICER to $\$$ I5 698. Hallan and associates ${ }^{37}$ reported SG estimates of o.9I and o.6r for minor and major stroke. Using these as utility weightings for stroke resulted in an ICER of \$I8 3I4 per QALY gained. Thomson and associates ${ }^{38}$ published SG utilities of 0.189 for a major stroke, 0.64 for a minor stroke and 0.84 for hemorrhage. These utility weightings gave an ICER of \$I4 544 per QALY gained.

A period of one year resulted in an ICER of $\$ 236667$ per QALY gained. Self-management becomes a more attractive option after 2 and 3 years with expected ICERs of $\$ 75882$ and $\$ 34484$ per QALY gained respectively. The cost-effectiveness of self-management over ro years was \$2995 per QALY benefit, assuming the point-of-care device would not have to be replaced.

\section{Interpretation}

Our analysis used a Bayesian framework to incorporate costs and QALYs into a fully probabilistic Markov model that examined self-managed oral anticoagulation therapy. The expected ICER was \$I4 I29 per QALY gained over 5 years. Our model was robust to varying assumptions of resource utilization, the discount rate and quality of life. Although the threshold of what decisionmakers are willing to pay for a QALY is a value judgment, in Canada it is generally accepted that a threshold of $\$ 50$ ooo per QALY represents good value given scarce health resources. ${ }^{39}$ Therefore, over a 5 -year period, our model suggests that self-management is a cost-effective option for a patient population taking warfarin for a mechanical heart valve or for atrial fibrillation.

Our study builds on previous economic evaluations in a number of important ways. Taborski and colleagues ${ }^{40}$ reported that self-management was cost-saving over Io years but did not consider differences in QALYs or adverse events forgone. Müller and colleagues ${ }^{4 \mathrm{I}}$ reported an ICER (Deutsche Marks [DM], year of currency not reported) of DMI05 000 per life-year gained, but the main limitation to this study was using life-year gained as the primary outcome measure. Life-year gained will likely underestimate quality-of-life 
gains under a self-management strategy because differences in quality-of-life will be significant owing to avoidance of major disability. The US perspective on physician management versus management at an anticoagulation clinic, and anticoagulation clinic versus self-testing was explored by Lafata and colleagues; ${ }^{42}$ this model used limiting assumptions for time in therapeutic range (i.e., 90\% of time in therapeutic range for self-testing).

A limitation of our model is that it may not be applicable to all clinical populations with an indication for chronic anticoagulation therapy. This lack of generalizability is because the trial at the $\mathrm{VGH}^{4}$ followed strict inclusion criteria. Inclusion criteria are necessary because the feasibility of self-management is dependent on the patient's ability to understand the concept of oral anticoagulant therapy and its potential risks as well as on adequate manual dexterity and sharpness of vision. ${ }^{25}$ As such, although self-management appears to be economically attractive, it is unlikely that it will replace physician management for all patients.

A second limitation is that patient preferences for using the point-of-care device were not modelled. Although the ability of patients to successfully self-manage warfarin therapy is independent of age, ${ }^{25}$ preferences for either management strategy may vary depending on age, confidence of participants, education level or comorbidity. We hypothesize it is these preferences that account for the high drop-out rate experienced (up to $20 \%$ ) in previous self-management trials. ${ }^{4,7}$ Subsequent economic analysis should stratify cost-effectiveness by indication and by preference for using the point-ofcare device. This will aid in informing clinicians and decision-makers on which patients are most likely to benefit from self-management.

\section{This article has been peer reviewed.}

From the Collaboration for Outcomes Research and Evaluation, Centre for Clinical Epidemiology and Evaluation, Vancouver Coastal Health Research Institute (Regier, Lynd, Marra), the Faculty of Pharmaceutical Sciences (Sunderji, Lynd, Marra), and the University of British Columbia Post-graduate Cardiology Training Program and Faculty of Medicine (Gin), University of British Columbia; and CSU Pharmaceutical Sciences (Sunderji) and the Coronary Care Unit and Echocardiography Laboratory (Gin), Vancouver General Hospital, Vancouver, BC

\section{Competing interests: None declared.}

Contributors: Dean Regier conducted the research, developed the cost-effectiveness model, developed and programmed the Bayesian Markov Model and wrote the manuscript. Rubina Sunderji provided expert opinion on self-managed oral anticoagulant therapy and event rates and contributed to the revision and intellectual content of the manuscript. Larry Lynd provided expert opinion on the epidemiology and health economic aspects of the model and revised the manuscript critically for content. Kenneth Gin provided expert opinion on event rates and revised the manuscript critically for content. Carlo Marra provided expert opinion on Bayesian Markov modelling, clinical event rates and health economics, and contributed to the critical revision and intellectual content of the manuscript. All of the authors gave final approval of the version to be published.

Acknowledgements: This work was presented at The 2nd Annual Canadian Therapeutics Congress on Apr. I8, 2005, at the Renaissance Harbourside Hotel in Vancouver, BC.

This work was supported by a Grant-in-Aid from the Heart and Stroke Foundation of British Columbia and Yukon. Larry Lynd and Carlo Marra are supported by the Michael Smith Foundation for Health Research Scholar Awards.

\section{REFERENCES}

I. Ansell J, Hirsh J, Poller L, et al. The pharmacology and management of the vitamin K antagonists: the Seventh ACCP Conference on Antithrombotic and Thrombolytic Therapy. Chest 2004;126(3 Suppl):204S-33S.

2. Hirsh J, Dalen J, Anderson DR, et al. Oral anticoagulants: mechanism of action, clinical effectiveness, and optimal therapeutic range. Chest 200I;IIg(I Suppl):8S-2IS.

3. Samsa GP, Matchar DB. Relationship between test frequency and outcomes of anticoagulation: a literature review and commentary with implications for the design of randomized trials of patient self-management. J Thromb Thrombolysis 2000;9: 283-92.

4. Sunderji R, Gin K, Shalansky K, et al. A randomized trial of patient self-managed versus physician-managed oral anticoagulation. Can J Cardiol 2004;20:III7-23

5. Cromheecke ME, Levi M, Colly LP, et al. Oral anticoagulation self-management and management by a specialist anticoagulation clinic: a randomised cross-over comparison. Lancet 2000;356:97-I02.

6. Fitzmaurice DA, Murray ET, Gee KM, et al. A randomised controlled trial of patient self management of oral anticoagulation treatment compared with primary care management. JClin Pathol 2002;55:845-9.

7. Menendez-Jandula B, Souto JC, Oliver A, et al. Comparing self-management of oral anticoagulant therapy with clinic management: a randomized trial. Ann Intern Med 2005;I42:I-IO.

8. Sawicki PT. A structured teaching and self-management program for patients receiving oral anticoagulation: a randomized controlled trial. Working Group for the Study of Patient Self-Management of Oral Anticoagulation. JAMA I999;28I: I45-50.

9. Sidhu P, O'Kane HO. Self-managed anticoagulation: results from a two-year prospective randomized trial with heart valve patients. Ann Thorac Surg 2001;72: I523-7.

Io. Voller H, Glatz J, Taborski U, et al. Self-management of oral anticoagulation in nonvalvular atrial fibrillation (SMAAF study). Z Kardiol 2005;94:182-6.

II. Koertke H, Minami K, Bairaktaris A, et al. INR self-management following mechanical heart valve replacement. J Thromb Thrombolysis 2000;9(Suppl I):S4I-5.

I2. Hasenkam JM, Kimose HH, Knudsen L, et al. Self management of oral anticoagulant therapy after heart valve replacement. Eur J Cardiothorac Surg I997;11:935-42.

I3. Ansell JE, Patel N, Ostrovsky D, et al. Long-term patient self-management of oral anticoagulation. Arch Intern Med 1995;155:2185-9.

I4. Heneghan C, Alonso-Coello P, Garcia-Alamino JM, et al. Self-monitoring of ora anticoagulation: a systematic review and meta-analysis. Lancet 2006;367:404-II.

I5. Rosendaal FR, Cannegieter SC, van der Meer FJ, et al. A method to determine the optimal intensity of oral anticoagulant therapy. Thromb Haemost 1993;69:236-9.

I6. Statistics Canada. Life tables: Canada, provinces, territories, I995-I997. Ottawa; 2002. Report no. 84-537-XIE.

17. Report from the Canadian Coordinating Office for Health Technology Assessment (CCOHTA). Guidelines for economic evaluation of pharmaceuticals: Canada. Int Technol Assess Health Care I995;II(4):796-7.

I8. Briggs AH, Ades AE, Price MJ. Probabilistic sensitivity analysis for decision trees with multiple branches: use of the Dirichlet distribution in a Bayesian framework. Med Decis Making 2003;23:34I-50.

I9. Palareti G, Leali N, Coccheri S, et al. Bleeding complications of oral anticoagulant treatment: an inception-cohort, prospective collaborative study (ISCOAT). Italian Study on Complications of Oral Anticoagulant Therapy. Lancet I996;348:423-8.

20. Cannegieter SC, Rosendaal FR, Wintzen AR, et al. Optimal oral anticoagulant therapy in patients with mechanical heart valves. N EngI J Med I995;333:II-7.

2I. Weimar C, Kurth T, Kraywinkel K, et al. Assessment of functioning and disability after ischemic stroke. Stroke 2002;33:2053-9.

22. Mayo NE, Wood-Dauphinee S, Ahmed S, et al. Disablement following stroke. Disabil Rehabil 1999;2I:258-68.

23. Hankey GJ, Jamrozik K, Broadhurst RJ, et al. Long-term disability after first-ever stroke and related prognostic factors in the Perth Community Stroke Study, I989I99o. Stroke 2002;33:1034-40.

24. White RH, McKittrick T, Takakuwa J, et al. Management and prognosis of lifethreatening bleeding during warfarin therapy. National Consortium of Anticoagulation Clinics. Arch Intern Med 1996;156:1197-201.

25. Ansell J, Jacobson A, Levy J, et al. Guidelines for implementation of patient selftesting and patient self-management of oral anticoagulation. International consensus guidelines prepared by International Self-Monitoring Association for Oral Anticoagulation. Int J Cardiol 2005;99:37-45.

26. Adams HP Jr, Adams RJ, Brott T, et al. Guidelines for the early management of patients with ischemic stroke: A scientific statement from the Stroke Council of the American Stroke Association. Stroke 2003;34:1056-83.

27. Canadian Institute for Health Information. Health conditions: heart disease and stroke. I999. Available: http://secure.cihi.ca/cihiweb/dispPage.jsp?cw_page=statistics _results_topic_heartdisease_e\&cw_topic=Health\%20Conditions\&cw_subtopic=Heart \%20Disease\%20and\%20Stroke (accessed $2006 \mathrm{Apr} 27$ ).

28. Health Funding and Costing Branch. Government of Alberta. Health costing in Alberta. 2003. Available at: www.health.gov.ab.ca/resources/publications/Health Costing 2003.pdf (accessed 2006 May I8).

29. Post PN, Stiggelbout AM, Wakker PP. The utility of health states after stroke: a systematic review of the literature. Stroke 200I;32:1425-9.

30. Glick HA, Polsky D, Willke RJ, et al. A comparison of preference assessment instruments used in a clinical trial: responses to the visual analog scale from the EuroQol EQ-5D and the Health Utilities Index. Med Decis Making I999;19:265-75. 
3I. Van Exel NJ. Scholte op Reimer WJ, Koopmanschap MA. Assessment of poststroke quality of life in cost-effectiveness studies: the usefulness of the Barthel Index and the EuroQoL-5D. Qual Life Res 2004;13:427-33.

32. EuroQol - a new facility for the measurement of health-related quality of life. The EuroQol Group. Health Policy I990;16:199-208.

33. Drummond M, O'Brien B, Stoddart GL, et al. Methods for the economic evaluation of health care programmes. 2nd ed. Oxford University Press; 1997.

34. Teng J, Mayo NE, Latimer E, et al. Costs and caregiver consequences of early supported discharge for stroke patients. Stroke 2003;34:528-36.

35. Hollander M. Unfinished business: the case for chronic home care services, a policy paper. Victoria: Hollander Analytical Services; 2003.

36. Briggs AH, O'Brien BJ, Blackhouse G. Thinking outside the box: recent advances in the analysis and presentation of uncertainty in cost-effectiveness studies. Annu Rev Public Health 2002;23:377-40I.

37. Hallan S, Asberg A, Indredavik B, et al. Quality of life after cerebrovascular stroke: a systematic study of patients' preferences for different functional outcomes. J Intern Med I999;246:309-I6.

38. Thomson R, Parkin D, Eccles M, et al. Decision analysis and guidelines for anticoagulant therapy to prevent stroke in patients with atrial fibrillation. Lancet 2000;
355:956-62

39. Laupacis A, Feeny D, Detsky AS, et al. How attractive does a new technology have to be to warrant adoption and utilization? Tentative guidelines for using clinical and economic evaluations. CMAJ I992;146:473-8I.

40. Taborski U, Wittstamm FJ, Bernardo A. Cost-effectiveness of self-managed anticoagulant therapy in Germany. Semin Thromb Hemost 1999;25:103-7.

4I. Müller E, Bergemann R; GELIA Study Group. Economic analysis of bleeding and thromboembolic sequelae after heart valve replacement (GELIA 7). Eur Heart ) Suppl 200I; 3:Q65-9.

42. Lafata JE, Martin SA, Kaatz S, et al. Anticoagulation clinics and patient self-testing for patients on chronic warfarin therapy: A cost-effectiveness analysis. J Thromb Thrombolysis 2000;9(Suppl I):Si3-9.

Correspondence to: Dr. Carlo Marra, Vancouver Coastal Health Research Institute, 717 - West Ioth Ave., Vancouver BC V5Z IL8; fax $604875-5179$

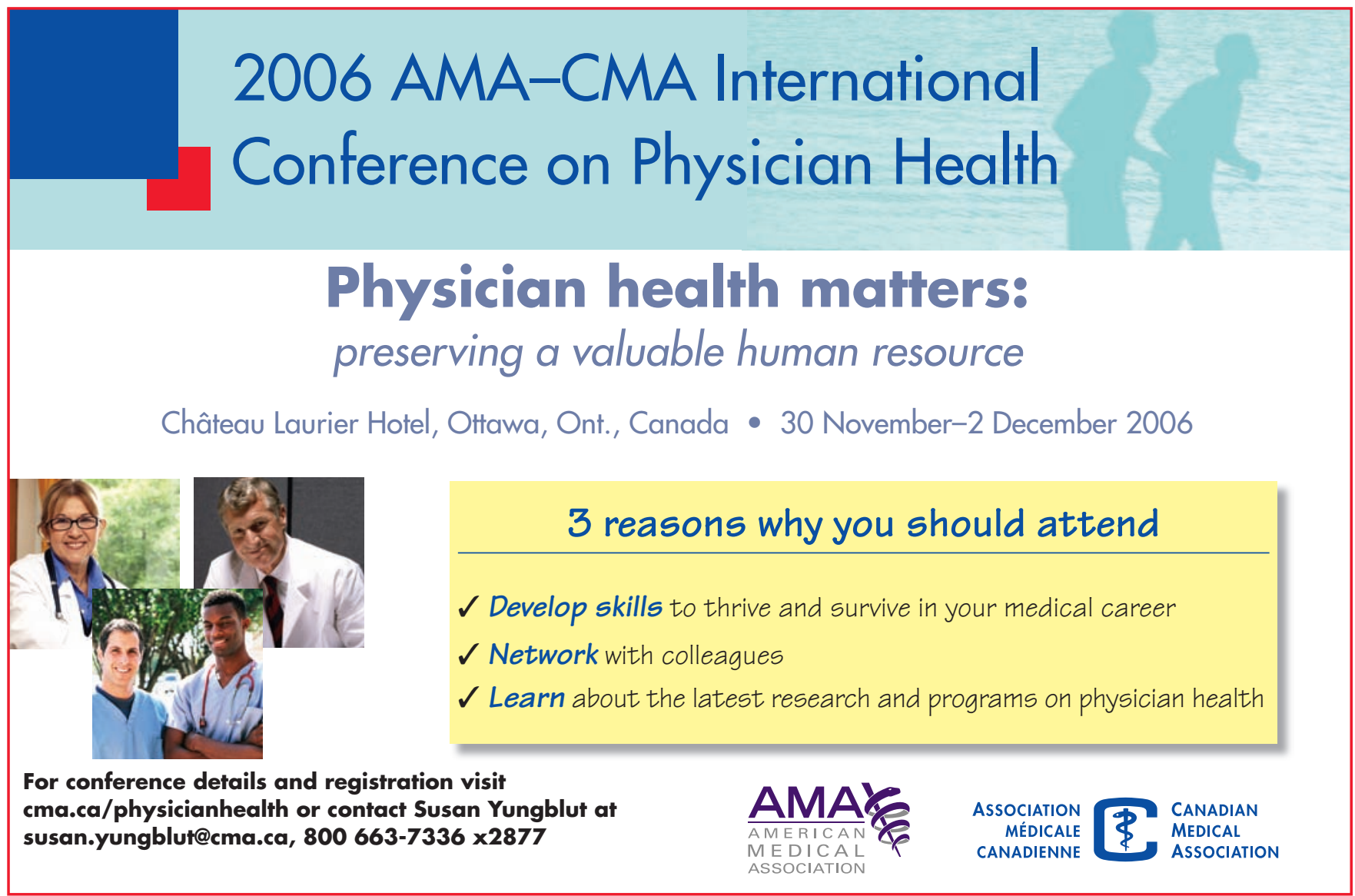

